\title{
EVALUATION OF THE ANTICARIOGENIC EFFECT OF NANO SILVER FLUORIDE ON DEMINERALIZATION OF ENAMEL IN PRIMARY TEETH (AN IN VITRO STUDY)
}

\author{
Dina I. El-Desouky ${ }^{1 *} B D S$, Azza Hanno ${ }^{2} P h D$, Karin M.L. Dowidar ${ }^{2} P h D$, Sara A. Hamza ${ }^{3}$ PhD, Lubna \\ M. El-Desouky ${ }^{4}$ BDS
}

\begin{abstract}
INTRODUCTION: Fluoride varnishes have proven to prevent dental decay. Alternative preparations that provide further benefits may be of interest to investigate.

AIM OF THE STUDY: was to compare the anticariogenic effect of Nano Silver Fluoride (NSF) with fluoride varnish (FV) on primary teeth enamel.

MATERIALS AND METHODS: Forty eight sound primary molars were coated with nail varnish, leaving squares of $4 \times 4 \mathrm{~mm}$ then sectioned longitudinally in a buccolingual direction into two equal halves. One half received a treatment and the other half remained untreated to serve as control. Each half was considered as a specimen (96 specimens). The NSF group ( $\mathrm{n}=48$ ) was subdivided into subgroup Ia $(n=24)$ treated with NSF and subgroup Ib $(n=24)$ served as negative control, the FV group ( $n=48)$ was subdivided into subgroup IIa $(\mathrm{n}=24)$ treated with FV and subgroup IIb $(\mathrm{n}=24)$ served as negative control. Specimens were subjected to $\mathrm{pH}$ cycling then they were examined with Vickers Microhardness device and Polarized Light Microscope.

REULTS: Percent difference in surface microhardness of subgroup Ia and subgroup Ib was 3.79 \pm 2.13 , while the percent difference

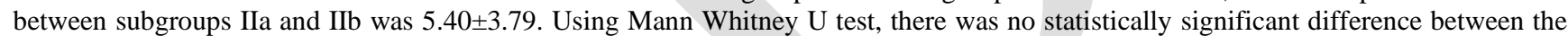
two values $(\mathrm{P}=0.81)$. The percent differences in lesion depth for subgroup Ia in comparison to Ib, and IIa in comparison to IIb were $36.36 \pm 9.54$ and $-37.30 \pm 16.67$ respectively. The difference between both values was non-significant $(\mathrm{P}=0.86)$.

CONCLUSIONS: NSF and FV are equally effective as anticariogenic materials that can limit enamel demineralization caused by cariogenic challenge.
\end{abstract}

${ }^{1}$ Dentist in the Egyptian Ministry of Health and Population

${ }^{2}$ Professor of Pediatric Dentistry, Faculty of Dentistry, Alexandria University, Alexandria, Egypt.

${ }^{3}$ Lecturer of Oral Biology, Faculty of Dentistry, Alexandria University, Alexandria, Egypt.

${ }^{4}$ Department of Pharmaceutics, Faculty of Pharmacy, Alexandria University, Alexandria, Egypt.

*Corresponding author:

Email: dinaeldosoki@gmail.com

\section{INTRODUCTION}

Dental caries is considered one of the most common chronic diseases of childhood (1). Taking into consideration that lower socioeconomic status is one of the risk factors of dental caries, dental researchers and clinicians faced the challenge of developing anti-caries agents that can reduce caries rates in underprivileged populations (2,3). As dental caries is a multi-factorial disease, many etiological factors contribute to the dental caries process such as diet, bacteria and the host. On the other hand, some factors are considered protective and when present, they reduce the incidence of dental caries (4).

For several years fluoride preparations have proven to prevent dental decay, and many professionally applied topical fluorides are available for this purpose. It has been found that the continuous exposure to low levels of fluoride is the most beneficial (5). However, in high caries risk patients the use of professionally applied high concentration fluoride treatments is highly recommended (6). One of these preparations is fluoride varnish (7). It was concluded in a systematic review that following treatment with fluoride varnish the caries prevented fraction for primary and permanent teeth was $37 \%$ and 43\% respectively (8). Despite its efficacy, fluoride varnish is expensive, technique sensitive and requires multiple applications per year; therefore alternative preparations that provide further benefits may be of interest (9).

Silver Diamine Fluoride (SDF) is one of the silver based fluoride preparations that is most widely tested. Some studies were conducted to evaluate the effect of SDF on the development of enamel carious lesions. Some of these studies concluded that SDF was 
El-desouky et al.

effective in preventing demineralization and gave effect that is comparable to FV $(10,11)$, whereas other studies considered SDF non effective as an anticariogenic agent when compared with fluoride varnish (12).

The reported side effects of SDF are the black staining of dental hard tissues and irritating soft tissues upon accidental contact (13). These drawbacks led to the consideration of another silver-based fluoride preparation which is Nano Silver Fluoride (NSF). Nano silver fluoride is an experimental formula obtained as a reddish yellow solution containing silver nanoparticles (AgNPs), chitosan and fluoride. It has cariostatic and antimicrobial properties and is considered to be an effective anti-caries agent that does not stain the porous dental tissues black and does not irritate the soft tissues as does silver diamine fluoride (14).

Thus, the present study aimed at comparing and evaluating NSF and FV as anticariogenic agents on primary teeth in vitro. The proposed null hypothesis was that NSF will have the same anticariogenic effect as that of fluoride varnish in preventing enamel caries in primary teeth.

\section{MATERIALS AND METHOD}

This in vitro experimental study was approved by the ethics committee in the Faculty of Dentistry Alexandria University. The minimal sample size was calculated based on a previous study (15). Calculation resulted in a standardized effect size $(\delta)$ of 0.915 that resulted in a minimum required sample size of 20 specimens per group (number of groups=2) so, total sample size needed $=40$ specimens $(16,17)$ as statistically significant with $80 \%$ power and at a significance level of $95 \%$ (alpha error accepted $=0.05$ ). Sample size per group was increased to 24 specimens per group (total sample size $=$ 48 specimens) (20\% increase) to control for elimination of specimens (attrition) bias (18). The sample size was calculated using IBM SPSS sample power 3.0.1.(2010) (19).

Forty eight human sound primary molars were collected and examined using a magnifying lens to ensure that these teeth met the inclusion criteria of having no caries or previous fillings and no developmental anomalies. The teeth were stored in $2 \%$ formaldehyde at room temperature till required for use (12). The teeth were randomly allocated using a computer-generated list of random numbers to one of the two treatment groups, where in group I the teeth were treated with NSF solution and in group II the teeth were treated with FV (15). A flow chart of the study design is shown in (figure 1)

Sample preparation:

The teeth were cleaned with fluoride free pumice then washed with distilled water and air-dried. A $4 \times 4 \mathrm{~mm}$ square of self-adhesive tapes were stuck at the center of the middle third of the buccal surface of each tooth (10). All surfaces of the teeth were coated with a layer of acid resistant nail varnish. When the nail varnish dried the selfadhesive tapes were removed leaving only a window of $4 \times 4$ $\mathrm{mm}$ of enamel exposed in each tooth (20). Each tooth was mounted in a self-cure acrylic resin inside a cylindrical plastic mold with its buccal surface facing upwards (21).
Anticariogenic effect of nano silver fluoride Each tooth was sectioned longitudinally in a buccolingual direction with a diamond disc mounted on a straight hand piece to obtain two equal halves where each half was considered as a specimen. Each two halves were kept together in a separate container, as one half was treated with the specific anticariogenic agent (group Ia and IIa) and the other half remained untreated and served as control (group Ib and IIb) (22). All the specimens were re-coated with nail varnish to cover any surface that has been exposed due to sectioning as well as the cut surface (15).

Nano Silver Fluoride preparation:

Nano silver fluoride was prepared in the laboratories of Faculty of Pharmacy, Alexandria University. Chitosan (28.7 $\mathrm{ml}, 2.5 \mathrm{mg} / \mathrm{ml}$ ) was first dissolved in 1\% acetic acid by stirring over night on a magnetic stirrer. Then, the chitosan mixture was filtered through a vacuum filter unit into a flask and transferred to an ice-cold bath. Under vigorous stirring, silver nitrate $(1 \mathrm{ml}, 0.11 \mathrm{~mol} / \mathrm{L})$ was added to the above mixture, then, freshly prepared sodium borohydride $(0.3 \mathrm{ml}, 0.8 \mathrm{~mol} / \mathrm{L})$ was added drop by drop. The reduction of $\mathrm{Ag}^{+}$was initiated immediately, as the solution changed from colourless to light yellow and ended up reddish. The flask was then removed from the ice bath and the sodium fluoride $(10,147 \mathrm{ppm}$ of fluorine) was incorporated (14).

\section{Characterization of NSF}

The size and morphology of AgNPs was characterized using field emission transmission electron microscope (TEM) (JEOL JEM-2100F) (3,23). The electron micrographs showed that most of the particles exhibited a spherical shape and more than $50 \%$ of the detected particles' size ranged from $13 \mathrm{~nm}$ to $16 \mathrm{~nm}$ (Figure 2).

Silver nano particles were also validated using UV/Vis spectrophotometer (Thermo Electron- Evolution 300) to detect the UV/Vis absorption spectrum of the resulting solution (14,24) (Figure 3) . The tested specimen exhibited a peak at $401 \mathrm{~nm}$ wavelength, which according to Agnihotri et al,2014 (25) denotes the presence of AgNPs with average size $15 \mathrm{~nm}$.

Grouping and Method

Application of the anticariogenic agents

Group I (NSF): In group Ia, the twenty-four specimens were treated with NSF. Each specimen received 2 drops of NSF solution using a micro brush on the exposed enamel windows of the buccal surfaces. The solution was left in contact with tooth surface for 2 minutes then rinsed with a flow of distilled water (15). In group Ib, the twenty-four specimens were left untreated to serve as negative controls.

Group II (FV): In group IIa, twenty-four specimens were treated with $5 \%$ sodium fluoride varnish (Profluorid ${ }^{\circledR}$, VOCO, Germany) according to the manufacturer's instructions. A thin uniform layer of fluoride varnish was applied to the exposed enamel windows using a disposable brush and the specimens were stored in artificial saliva for 24 hours (15). Afterward, the fluoride varnish was removed from the specimens' surfaces with a cotton swab soaked in acetone (21). In group IIb twentyfour specimens were left untreated to serve as negative controls.

pH cycling:

Over a period of seven days, all the specimens were subjected to $5 \mathrm{pH}$ cycles at $37^{\circ} \mathrm{C}$ followed by 2 days of 
El-desouky et al.

remineralization (26). Each specimen was stored in a separate container. Specimens were immersed in the demineralizing solution (calcium and phosphate, both 2.0 $\mathrm{mmol} / \mathrm{L}$, in $75 \mathrm{mmol} / \mathrm{L}$ acetate buffer, $\mathrm{pH} 4.7 ; 0.04 \mu \mathrm{g}$ $\mathrm{F} / \mathrm{mL}, 2.2 \mathrm{~mL} / \mathrm{mm}^{2}$ ) for 3 hours, followed by distilled water rinse. Then, they were immersed in remineralizing solution $\left(1.5 \mathrm{mM} \mathrm{CaCl}_{2}, 0.9 \mathrm{mM} \mathrm{NaH} \mathrm{PO}_{4}, 0.15 \mathrm{M} \mathrm{KCL}\right.$ had a $\mathrm{pH}$ of $7.0,1.1 \mathrm{ml} / \mathrm{mm}^{2}$ ) for 21 hours $(27,28)$.

Microhardness test evaluation

Twelve specimens from each test group (Ia, IIa) and their corresponding controls (Ib, IIb) $(n=48)$ were examined with Vickers Microhardness Device (Wilson microhardness tester, Japan) with a load of 50gm for 10 seconds. Three indentations were made in the enamel surface of each specimen then the mean was calculated and considered as the hardness number of the specimen (29).

Polarized light microscopic evaluation

The remaining specimens from each test group (Ia, IIa) and their corresponding controls (Ib, IIb) $(n=48)$ were prepared for analysis by polarized light microscope (Olympus America Inc.). Longitudinal ground sections of about $15 \mu \mathrm{m}$ thickness were prepared, and then mounted using Canada balsam to hold the specimen in place between the slip cover and the glass slide. Depth measurements were done using (image J.46) software (30). The mean depth of the enamel lesion of each specimen was measured by averaging of three lines: one at each side and one at the center of the lesion within the subsurface of the lesion body, perpendicular to the outer layer of the enamel surface and extending to the translucent band (Figure 4).

Statistical analysis

Data were analyzed by the use of SPSS software (SPSS version 25.0). Data were reviewed to check for any errors during data entry. Normality was checked using descriptive statistics, plots (histogram and box plot) and Shapiro Wilk test. Normally distributed data was presented using Mean \pm SD while median and inter quartile range (IQR) were used for not normally distributed data.

Differences in lesion depth and surface microhardness between test and control in NSF and fluoride varnish groups were analyzed using parametric test; paired $\mathrm{t}$ test while percent change in surface microhardness between NSF and fluoride varnish was assessed using Mann Whitney $\mathrm{U}$ test.

Percent change in lesion depth and surface microhardness between NSF and fluoride varnish groups relative to their controls was calculated according to the formula [(lesion depth in test-lesion depth in control)/lesion depth in control] x 100 and the same for enamel microhardness.

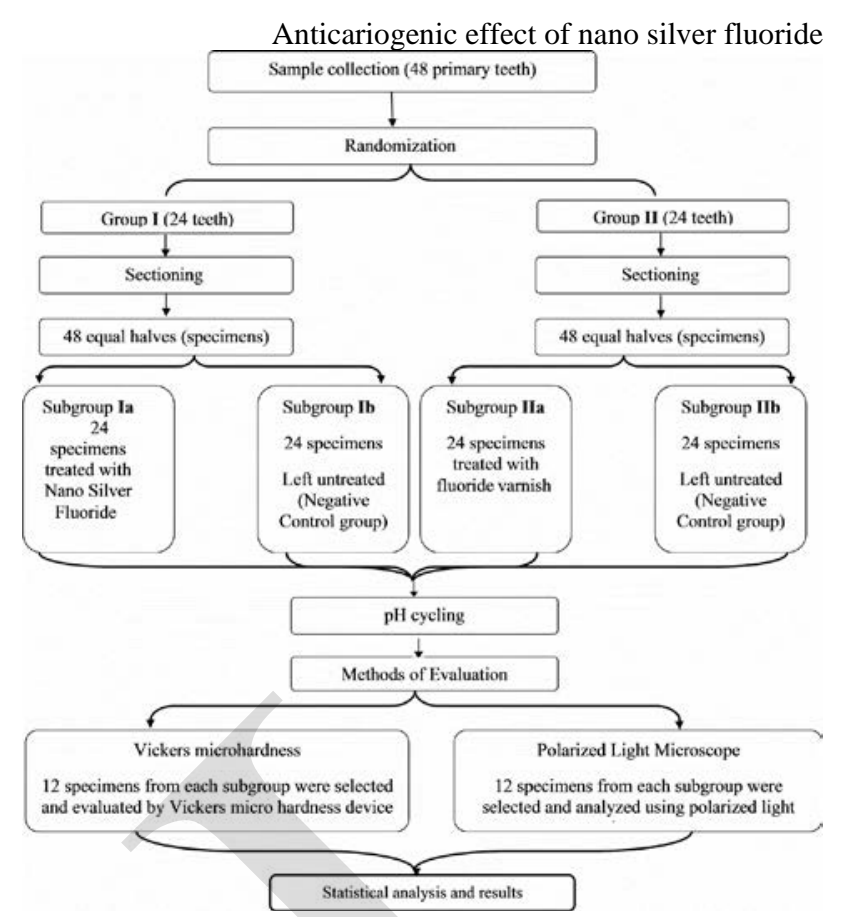

Figure 1: A flow chart of the study design

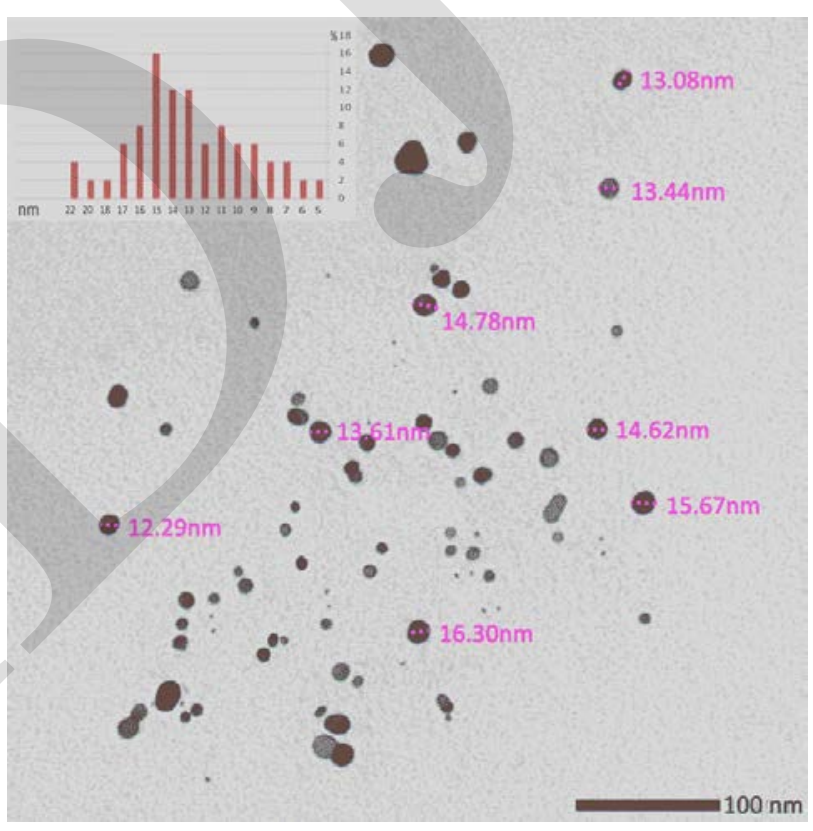

Figure 2: Transmission electron microgragh of silver nano particles in the prepared NSF and a histogram showing particle size distribution.

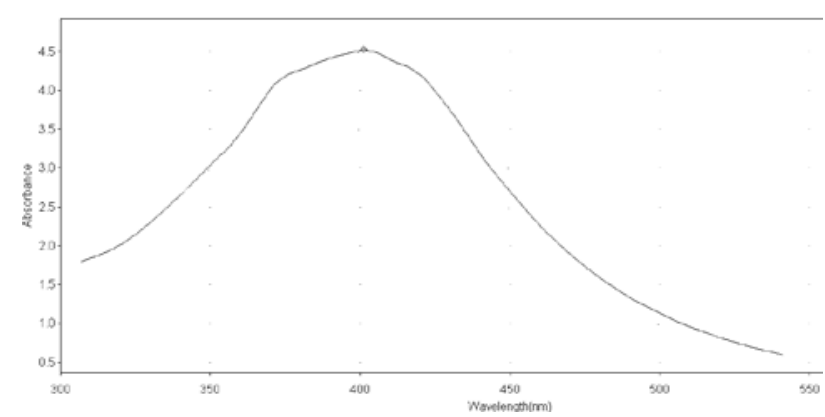

Figure 3: Ultraviolet-Visual spectrum of synthesized silver nanoparticles 


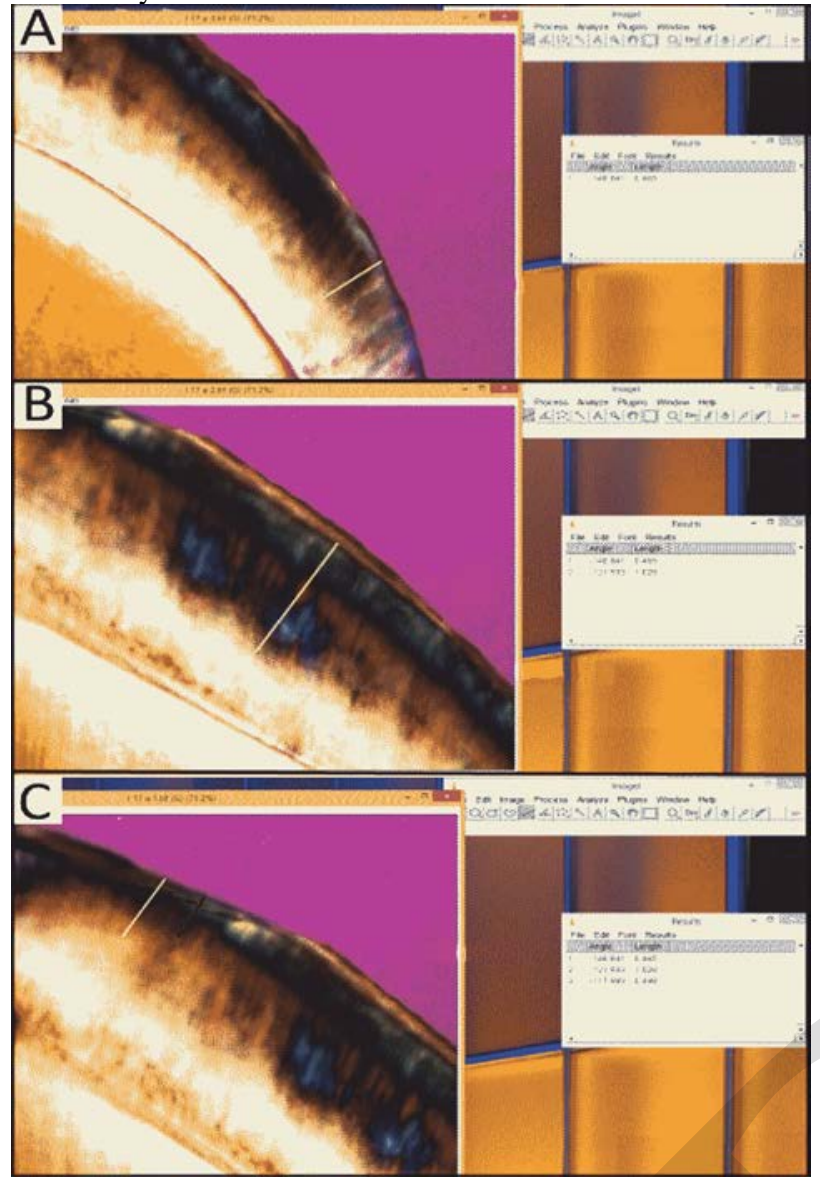

Figure 4: Transmitted light photomicrographs showing the use of (image J) software to measure the lesion depth, magnification X40. (A\&C): Sides of the lesion. (B):

Center of the lesion.

\section{RESULTS}

Surface microhardness (mean \pm SD) of all specimens are shown in (Table 1). The mean microhardness values in subgroup Ia and subgroup Ib were $312.75 \pm 26.35$ and $301.50 \pm 26.95$ respectively. Surface microhardness in subgroup Ia was higher than subgroup Ib, and the difference was statistically significant $(\mathrm{P}<0.001)$. On the other hand, the mean microhardness values were $309.27 \pm 22.53$ and $293.69 \pm 23.24$ for subgroups IIa and IIb respectively. Microhardness in subgroup IIa was higher than subgroup IIb and there was a statistically significant difference between the two subgroups $(\mathrm{P}<0.001)$. When the mean microhardness values of subgroup Ia (NSF) and subgroup IIa (FV) were compared, there was no statistically significant difference between the two subgroups $(\mathrm{P}=0.73)$. Percent difference between NSF test group (Ia) and its control group (Ib) was 3.79 \pm 2.13 , while the percent difference between FV test group (IIa) and its control (IIb) was $5.40 \pm 3.79$. The two values were compared and there was no statistically significant difference between the two values $(\mathrm{P}=0.81)$.

Lesion depth values of all groups are shown in (Table 2), and polarized light photo micrographs of one specimen of each group is shown in (Figure 5). The mean lesion depth of subgroup Ia was $244.03 \pm 79.73 \mu \mathrm{m}$, whereas in subgroup Ib was $384.30 \pm 110.91 \mu \mathrm{m}$. There was a decrease in lesion depth in subgroup Ia and the
Anticariogenic effect of nano silver fluoride difference was statistically significant $(\mathrm{P}<0.001)$. The mean lesion depth of subgroup IIa was 262.73 \pm 99.65 $\mu \mathrm{m}$, whereas in subgroup IIb was $416.96 \pm 107.42 \mu \mathrm{m}$. There was a statistically significant difference between the two subgroups, with a decrease in lesion depth in subgroup IIa $(\mathrm{P}<0.001)$. Lesion depth of subgroup Ia (NSF) and subgroup IIa (FV) were compared and there was no statistically significant difference between the two subgroups $(\mathrm{P}=0.61)$.

Percent difference between NSF test group (Ia) and its control group (Ib) was $-36.36 \pm 9.54$, whereas the percent difference between FV test group (IIa) and its control (IIb) was $-37.30 \pm 16.67$. There was no statistically significant difference between the two values $(\mathrm{P}=0.86)$.

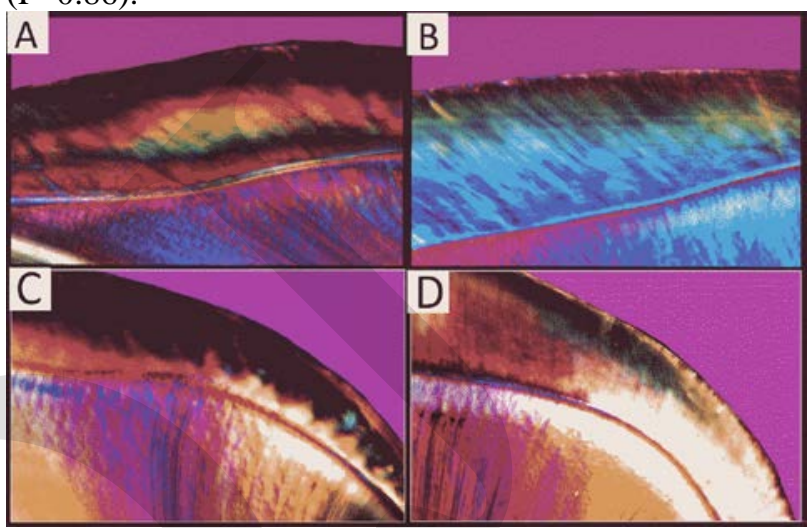

Figure 5: Polarized light photomicrograph of longitudinal ground sections of one specimen of each group showing (A): a specimen of the NSF control group(group Ib) showing an evident dark demineralized enamel band, (B): a specimen treated with NSF (group Ia) showing prominent reduction in the depth of the body of the lesion when compared in the control specimen,(C): a specimen of the FV control group (group IIb) showing the extent of the lesion that is almost reaching the amelodentinal junction, (D): a specimen treated with FV (group IIa) showing limitation in the extent of the lesion depth compared to the control specimen. Note the surface layer (red arrows) in (B\&D) which appears more mineralized compared to deeper area, magnification X40.

Table 1: Vickers microhardness values of all studied groups and percent difference between each test and its control group

\begin{tabular}{|c|c|c|c|c|c|}
\hline & & \multicolumn{2}{|c|}{$\begin{array}{c}\text { NSF (group Ia) } \\
n=24\end{array}$} & \multicolumn{2}{|c|}{$\begin{array}{c}\text { Fluoride varnish } \\
\text { (group IIa) } \\
\text { n=24 }\end{array}$} \\
\hline & & $\begin{array}{c}\text { Ia (test) } \\
\mathrm{n}=12\end{array}$ & $\begin{array}{c}\mathrm{Ib} \\
\text { (control) } \\
\mathrm{n}=12\end{array}$ & $\begin{array}{c}\text { IIa (test) } \\
\mathrm{n}=12\end{array}$ & $\begin{array}{c}\text { IIb(contr } \\
\text { ol) } \\
n=12\end{array}$ \\
\hline \multicolumn{2}{|c|}{ Mean \pm SD } & $\begin{array}{c}312.75 \pm \\
26.35\end{array}$ & $\begin{array}{c}301.50 \pm \\
26.95\end{array}$ & $\begin{array}{c}309.27 \pm \\
22.53\end{array}$ & $\begin{array}{c}293.69 \pm \\
23.24\end{array}$ \\
\hline \multicolumn{2}{|c|}{ Paired t } & \multicolumn{2}{|c|}{6.40} & \multicolumn{2}{|c|}{5.35} \\
\hline \multicolumn{2}{|c|}{ P value } & \multicolumn{2}{|c|}{$<0.001^{*}$} & \multicolumn{2}{|c|}{$<0.001^{*}$} \\
\hline \multirow{5}{*}{$\begin{array}{l}\text { Perce } \\
\text { nt } \\
\text { differ } \\
\text { ence }\end{array}$} & $\begin{array}{l}\text { Mean } \\
\pm \text { SD }\end{array}$ & \multicolumn{2}{|c|}{$3.79 \pm 2.13$} & \multicolumn{2}{|c|}{$5.40 \pm 3.79$} \\
\hline & $\begin{array}{c}\text { Media } \\
\mathrm{n}\end{array}$ & \multicolumn{2}{|c|}{3.23} & \multicolumn{2}{|c|}{4.17} \\
\hline & IQR & \multicolumn{2}{|c|}{$2.54-4.39$} & \multicolumn{2}{|c|}{$3.18-6.37$} \\
\hline & MWU & \multicolumn{4}{|c|}{-1.328} \\
\hline & $\begin{array}{c}\mathrm{P} \\
\text { value }\end{array}$ & \multicolumn{4}{|c|}{0.81} \\
\hline
\end{tabular}


*Statistically significant at $\mathrm{p}$ value $\leq 0.05$

NSF: Nano silver fluoride

MWU: Mann Whitney U test

Table 2: Lesion depth values of of all studied groups and percent difference between each test and its control group

\begin{tabular}{|c|c|c|c|c|c|}
\hline & & \multicolumn{2}{|c|}{$\begin{array}{c}\text { NSF (group Ia) } \\
n=24\end{array}$} & \multicolumn{2}{|c|}{$\begin{array}{l}\text { Fluoride varnish } \\
\text { (group IIa) } \\
n=24\end{array}$} \\
\hline & & $\begin{array}{l}\text { Ia (test) } \\
n=12\end{array}$ & $\begin{array}{c}\mathrm{Ib} \\
\text { (control } \\
\text { ) }_{\mathrm{n}=12}\end{array}$ & $\begin{array}{c}\text { IIa } \\
\text { (test) } \\
n=12\end{array}$ & $\begin{array}{c}\text { IIb(cont } \\
\text { rol) } \\
n=12\end{array}$ \\
\hline \multicolumn{2}{|c|}{ Mean \pm SD } & $\begin{array}{c}244.03 \\
\pm 79.73 \\
\mu \mathrm{m}\end{array}$ & $\begin{array}{c}384.30 \pm \\
110.91 \\
\mu \mathrm{m}\end{array}$ & $\begin{array}{c}262.73 \\
\pm 99.65 \\
\mu \mathrm{m}\end{array}$ & $\begin{array}{c}416.96 \pm \\
107.42 \\
\mu \mathrm{m}\end{array}$ \\
\hline \multicolumn{2}{|c|}{ Paired t } & \multicolumn{2}{|c|}{-8.56} & \multicolumn{2}{|c|}{-6.65} \\
\hline \multicolumn{2}{|c|}{$\mathrm{P}$ value } & \multicolumn{2}{|c|}{$<0.001^{*}$} & \multicolumn{2}{|c|}{$<0.001^{*}$} \\
\hline \multirow{3}{*}{$\begin{array}{l}\text { Perce } \\
\text { nt } \\
\text { differ } \\
\text { ence }\end{array}$} & $\begin{array}{c}\text { Mean } \\
\pm \text { SD }\end{array}$ & \multicolumn{2}{|c|}{$-36.36 \pm 9.54$} & \multicolumn{2}{|c|}{$-37.30 \pm 16.67$} \\
\hline & t test & \multicolumn{4}{|c|}{0.169} \\
\hline & $\begin{array}{c}\mathrm{P} \\
\text { value }\end{array}$ & \multicolumn{4}{|c|}{0.86} \\
\hline
\end{tabular}

*Statistically significant at $p$ value $\leq 0.05$

NSF: Nano silver fluoride

$\mathrm{t}$ test: Student's t test

\section{DISCUSSION}

In this study, nano silver fluoride solution was compared to $5 \%$ sodium fluoride varnish to evaluate their anticariogenic effect on carious lesion formation. The results were in favor of the null hypothesis, where NSF solution and FV had a positive effect on enamel demineralization when applied to the teeth before the acidic challenge. Thus proving their preventive effect on lesion formation especially when compared to the untreated specimens in which enamel demineralization was more evident with an increased lesion depth formation.

Nano silver fluoride is a new experimental material that has been developed originally to arrest progression of cavitated carious lesions in the same manner as silver diamine fluoride (3). The preparation of NSF was carried out according to the method described by Targino et al, 2014 (14). The synthesis of aqueous solution of silver nanoparticles was carried out via the chemical reduction of silver nitrate with sodium borohydride and chitosan biopolymer as a carrier for the silver nano particles, to improve the molecular weight and to stabilize the compound. The addition of sodium fluoride aimed at enhancing the antibacterial effect of the compound in addition to favoring remineralization and inhibiting demineralization which occur continuously in the oral environment (31).

The $\mathrm{pH}$ cycling model applied in the present study (26) was introduced in order to produce a sub-surface lesion similar to incipient carious lesions that occur in vivo, and accurately predict the effect of fluoride containing products.
In this model the specimens were kept in remineralizing solution for the last 2 days of $\mathrm{pH}$ cycling $\left(6^{\text {th }}\right.$ and $7^{\text {th }}$ days). This step was relevant to preserve the enamel surface layer allowing accurate SMH determination.

In the present study, the effect of NSF on enamel demineralization was assessed by evaluating its effect on surface microhardness and the treated specimens showed a higher surface microhardness values in comparison to the untreated ones. Likewise, the results of lesion depth revealed the ability of NSF solution to resist enamel demineralization in the treated specimens. The specimens showed some degree of demineralization as evident by the formation of caries-like lesions, these lesions were about $36 \%$ less in depth when compared to the untreated specimens. In line with these results, Teixeira et al in 2018 (23) showed that NSF was more effective in decreasing enamel demineralization after $\mathrm{pH}$ cycling than the negative control sample.

Fluoride varnish was regarded as a control because it is one of the most studied preparations, has proved to be safe, and well tolerated by children. In addition, it is recommended by the American Academy of Pediatric Dentistry (AAPD) (32) for use for children younger than 6 years due to its proved efficacy in preventing dental caries in children at high caries risk. Fluoride varnish was also tested in the current study and the results showed its ability to decrease demineralization in the treated specimens. Mean microhardness value of the treated specimens was about 5\% higher than that of untreated specimens and lesion depth in FV treated specimens was 37\% lower than that of untreated specimens. Mohammadi and Farahmand Far in 2018 (21) assessed the effect of fluoridated varnish on enamel demineralization resistance in enamel of primary teeth and their results showed that microhardness values of the treated group were about $3 \%$ higher than the untreated ones.

The fluoride content of the NSF that was used in the current study was 10,147 ppm of fluorine, whereas, the fluorine content in the FV was 22,600 ppm. In addition, the contact time of NSF with tooth structure was only two minutes while it was 24 hours with the FV. Despite these above dissimilarities, that might seem in favor of the FV, the NSF showed a preventive capacity that is comparable to the FV. This is evident by the study results, which proved both NSF and fluoride varnish were effective in resisting demineralization of primary enamel with no significant difference even though the FV showed a higher percentage of microhardness variation and difference in lesion depth. The protective effect of NSF could be explained by the very small particle size of AgNPs which facilitated the penetration of the material into the enamel structure leading to maximizing its protective effect (33).

Similarly, in a study by Teixeira et al, 2018 (23), the results showed no statistically significant difference between NSFcontaining dentifrice and sodium fluoride $(\mathrm{NaF})$ dentifrice in preventing demineralization, although the results showed that $\mathrm{NaF}$ has lower percentage of microhardness variation. This could be explained by the different $\mathrm{pH}$ cycling protocol used and the repeated application of dentifrice slurries before each pH cycle, which could have accentuated the effect of the used materials.

On the other hand, in the study by Nozari et al in 2017 (15) the results revealed that specimens treated with NSF had the highest surface microhardness values 
El-desouky et al. compared with fluoride varnish and nano hydroxyapatite paste. This result could be related to the different study design which focused on comparing remineralization of the preformed enamel caries lesion, not the ability of the tested materials to prevent demineralization of enamel.

It was noticed from the results of the present study that the groups that had the highest microhardness values (group Ia and group IIa) had the lowest values of lesion depth and vice versa. This finding implies that specimens with higher microhardness had higher resistance against carious lesion formation, thus having less lesion depth. This might be attributed to the formation of a highly mineralized surface layer that resulted from direct contact with materials having high fluoride content (34) (Figure 5). In addition, the $\mathrm{pH}$ cycling model that was used in the present study had alternating demineralization and remineralization phases. This cycling model had the purpose of preserving the enamel surface layer and create a sub-surface lesion that closely imitates the natural incipient carious lesion $(4,26,35)$. This behavior might have led to a surface layer that had a relatively high microhardness value and a sub-surface lesion that was evident in the polarized light microscope. The limitations of this study were the difficulty in reproducing the oral environment including the biofilm and oral flora, different salivary components, individuals eating habits and oral hygiene practices. In addition, the present study was limited to a period of 7 days, while the de/remineralization processes are long-term processes.

In conclusion, the present results support the anticariogenic effect of NSF; however, further studies are recommended to evaluate the oral factors, the anti-microbial potential and the safety in clinical settings.

\section{CONCLUSIONS}

Based on the results of this in vitro study, it was concluded that:

Both Nano Silver Fluoride and Fluoride Varnish are equally effective as anticariogenic materials that can limit enamel demineralization caused by cariogenic challenge.

Both tested materials were not able to provide complete protection against demineralization.

Nano silver fluoride could be used as an alternative to FV. CONFLICT OF INTEREST

The authors declare that they have no conflicts of interest.

\section{REFERENCES}

1. Petersen PE. The World Oral Health Report 2003. World Heal Organ. 2003;1-38.

2. Dean JA, Jones JE, Vinson LAW, McDonald RE. McDonald and Avery's dentistry for the child and adolescent. 10th ed. Dean J, editor. Elsevier Ltd; 2016.

3. Dos Santos VE, Filho AV, Ribeiro Targino AG, Pelagio Flores MA, Galembeck A, Caldas AF, et al. A new "silver-Bullet" to treat caries in children Nano Silver Fluoride: A randomised clinical trial. J Dent. 2014;42:945-51.

4. Fejerskov O, Kidd E. Dental caries: the disease and its clinical management. 2nd ed. Fejerskov O, Kidd E, editors. blackwell munksgaard; 2008.
Anticariogenic effect of nano silver fluoride

5. O’Mullane DM, Baez2 RJ, Jones S, Lennon MA, Petersen PE, RuggGunn AJ, et al. fluoride and oral health. Community Dent Health. 2016;33:69-99.

6. American-Dental-Association. Professionally applied topical fluoride: Evidence-based clinical recommendations. J Am Dent Assoc. 2006;137:1151-9.

7. Øgaard B, Seppä L, Rolla G. Professional Topical Fluoride Applications- Clinical Efficacy and Mechanism of Action. Adv Dent Res. 1994;8:190201.

8. Marinho VC, Worthington H V, Walsh T, Clarkson JE. Fluoride varnishes for preventing dental caries in children and adolescents. Cochrane Database Syst Rev. 2013 Jul 11; CD002279.

9. Burns J, Hollands K. Nano Silver Fluoride for preventing caries. Evid Based Dent. 2015;16:8-9.

10. Santos L de M, Reis JIL dos, Medeiros MP de, Ramos SM, Araújo JM de. In vitro evaluation of fluoride products in the development of carious lesions in deciduous teeth. Braz Oral Res. 2009;23:296-301.

11. Yu D-G, Kimura Y, Fujita A, Hossain M, Kinoshita J-I, Suzuki N, et al. Study on Acid Resistance of Human Dental Enamel and Dentin Irradiated by Semiconductor Laser with Ag(NH 3 ) 2 F Solution . J Clin Laser Med Surg. 2002;19:141-6.

12. Delbem ACB, Bergamaschi M, Sassaki KT, Cunha RF. Effect of fluoridated varnish and silver diamine fluoride solution on enamel demineralization: $\mathrm{pH}$ cycling study. J Appl Oral Sci. 2006;14:88-92.

13. Rosenblatt A, Stamford TCM, Niederman R. Silver diamine fluoride: A caries "silver-fluoride bullet.” J Dent Res. 2009;88:116-25.

14. Targino AGR, Flores MAP, Dos Santos VE, De Godoy Bené Bezerra F, De Luna Freire $H$, Galembeck A, et al. An innovative approach to treating dental decay in children. A new anti-caries agent. J Mater Sci Mater Med. 2014;25:2041-7.

15. Nozari A, Ajami S, Rafiei A, Niazi E. Impact of nano hydroxyapatite, nano silver fluoride and sodium fluoride varnish on primary enamel remineralization: An in vitro study. J Clin Diagnostic Res. 2017;11:ZC97-100.

16. Killeen PR. An Alternative to Null-Hypothesis Significance Tests. Psychol Sci. 2005;16:345.

17. Daniel WW. Biostatistics: A foundation for analysis in the health sciences. $10^{\text {th }}$ ed. John Wiley \& Sons; 2013

18. Pannucci CJ, Wilkins EG. Identifying and Avoiding Bias in Research. Plast Reconstr Surg. 2010;126:619.

19. Faul F, Erdfelder E, Lang A-G, Buchner A. G*Power 3: A flexible statistical power analysis program for the social, behavioral, and biomedical sciences. Behav Res Methods. 2007 May;39:175-91.

20. De Gauw JH, Costa LMM, Silva RN, Santos NB, Tenorio MDH. Evaluation of the Effect of Ferrous Sulfate on Enamel Demineralization of Human Deciduous Teeth: an in Vitro Study. Rev Bahiana Odontol. 2017;8: 70-76.

21. Mohammadi N, MH Farahmand Far. Effect of fluoridated varnish and silver diamine fluoride on enamel demineralization resistance in primary 
El-desouky et al. dentition Najmeh. J Indian Soc Pedod Prev Dent. 2018;36:257-61.

22. Duggal M, Toumba K, Amaechi B, Kawash M, Higham S. Enamel demineralization in situ with various frequencies of carbohydrate consumption with and without fluoride toothpaste. J Dent Res. 2001;80:1721-4.

23. Teixeira JA, Costa E Silva AV, Dos Santos VE, De Melo PC, Arnaud M, Lima MG, et al. Effects of a New Nano-Silver Fluoride-Containing Dentifrice on Demineralization of Enamel and Streptococcus mutans Adhesion and Acidogenicity. Int J Dent. 2018;2018.

24. Wei D, Sun W, Qian W, Ye Y, Ma X. The synthesis of chitosan-based silver nanoparticles and their antibacterial activity. Carbohydr Res. 2009;344:2375-82.

25. Agnihotri S, Mukherji S, Mukherji S. Size-controlled silver nanoparticles synthesized over the range 5-100 $\mathrm{nm}$ using the same protocol and their antibacterial efficacy. RSC Adv. 2014;4:3974-83.

26. Vieira AE, Delbem AC, Sassaki KT, Rodrigues E, Cury JA, Cunha RF. Fluoride dose response in $\mathrm{pH}-$ cycling models using bovine enamel. Caries Res. 2005;39:514-20.

27. ten Cate JM, Duijsters PP. alternating demineralization and remineralization of artificial enamel lesions. Caries Res. 1982;16:201-10.

28. Buzalaf MAR, Hannas AR, Magalhães AC, Rios D, Honório HM, Delbem ACB. pH-cycling models for in vitro evaluation of the efficacy of fluoridated dentifrices for caries control: strengths and limitations. J Appl Oral Sci. 2010;18:316-34.
Anticariogenic effect of nano silver fluoride

29. Cury J, Amaral R, Tenuta L, Del Bel Cury A, Tabchoury C. Low-fluoride toothpaste and deciduous enamel demineralization under biofilm accumulation and sucrose exposure. Eur J Oral Sci. 2010;118:3705.

30. De Campos PH, Sanabe ME, Rodrigues JA, Duarte DA, Santos MTBR, Guaré RO, et al. Different bacterial models for in vitro induction of noncavitated enamel caries-like lesions: Microhardness and polarized light miscroscopy analyses. Microsc Res Tech. 2015 Jun;78:444-51.

31. Featherstone JDB. The science and practice of caries prevention. J Am Dent Assoc. 2000;131:887-99.

32. American Academy of Pediatric Dentistry. Fluoride Therapy. Ref Man. 2018;40:250-3.

33. Corrêa JM, Mori M, Sanches HL, Cruz AD Da, Poiate E, Poiate IAVP. Silver nanoparticles in dental biomaterials. Int J Biomater. 2015;2015(Article ID 485275).

34. Tenuta LMA, Cury JA. Fluoride: its role in dentistry. Braz Oral Res. 2010;24:9-17.

35. White DJ. The Application of in Vitro Models to Research on Demineralization and Remineralization of the Teeth. Adv Dent Res. 1995 Nov;9:175-93. 